\title{
The Theory and Practice of Narrative in Plato
}

\author{
Stephen Halliwell
}

All narrative discourse, from the simplest to the most sophisticated, imposes a perspectival structure on temporal experience. To that extent, all narrative can be categorised and analysed, as the powerful tools of modern narratology have demonstrated, in terms of the operation of a number of variable features of discursive form and focus. But because narrativity is so ineliminable from the fabric of human awareness, its ramifications have a tendency to outreach the scope of systematic codification. The fluidity and open-endedness of consciousness, memory, and imagination are entangled with, but also partly resistant to, the organising configurations of narrative. This tension generates a complex web of possibilities whose very richness gives narratological methods much of their raison d'être and interest. At the same time, however, it provides reasons to question whether narrative, in all its shapes and sizes, could ever be comprehensively theorised.

Since the present chapter is concerned with some of the relations between the theory and practice of narrative in Plato, it may be fruitful to start with an illustration taken from one of the most intriguingly designed narrative constructions to be found anywhere in the Platonic corpus, the opening of the Theaetetus. The main body of the dialogue is framed (or, more strictly, half-framed, since the work ends without a return to the opening interlocutors) by a conversation between two Megarians, Euclides and Terpsion. Euclides recounts to his friend that he has just returned to town after a chance encounter with the Athenian Theaetetus, who had been seriously wounded in battle against the Corinthians and was being taken home to his native city. Euclides goes on to explain how, after leaving Theaetetus (and after urging him in vain to stay and recuperate at Megara), his mind flooded with thoughts of a philosophical discussion in which Theaetetus had once participated with Socrates, shortly before the latter's death, and of which Euclides

I am very grateful to Professors Antonios Rengakos and Jonas Grethlein for inviting me to contribute to the stimulating Thessaloniki narratology conference in December 2007. I thank my fellow participants for discussion of my paper. 
had received lengthy descriptions, on several occasions, from Socrates himself. So fascinated was Euclides by what he was told about this discussion that he had reconstructed it over a period of time in writing, turning it into a dramatic dialogue whose accuracy he had checked and corrected in direct consultation with Socrates. That written account is presented as the main substance of the Theaetetus itself: Euclides agrees to Terpsion's request to hear the dialogue, which is read to them by Euclides' slave.

In formal terms, therefore, Plato's Theaetetus comprises a conversation between characters who then listen to the recital of a reconstructed version of a previous conversation between several other characters. As with the more commonly cited but in some ways less remarkable opening of the Symposium, this layered or 'parenthetic' construction is notable for its literary intricacy and self-consciousness: there is an obvious mise-en-abyme effect in the fact that Plato's dialogue largely consists of (an oral presentation of) Euclides' own dialogue. But this compositional structure, which can be analysed from various angles as a narrative strategy, sets up a depth of perspective whose psychological expressiveness and emotional resonance are less easy to fix or delimit. It is immediately after saying farewell to Theaetetus (and at a place which for some of Plato's readers may have had mythological associations with death), ${ }^{1}$ and in a spontaneous surge of highly charged recollection, that Euclides starts to remember Socrates - in particular, his prescience of a future he did not live to see: 'I recalled and marvelled at how prophetic Socrates was about Theaetetus, among many other things' (Tht. 142c). This memory is in turn tied up with the degree to which Euclides had been captivated by Socrates' accounts of his first conversation with Theaetetus, a response which had motivated his decision to produce a written version of that conversation. The literary layers of Plato's dialogic composition are matched, in other words, but also expanded by the layers of associative memory revealed by Euclides' remarks to his friend Terpsion. And there is a further element to this aspect of the work. The text invites its readers to suppose (and some of the earliest readers

1 It is possible, though not certain, that Erinus/-um, Tht. 143b1, is the same place as the Erineus, at Eleusis, mentioned at Paus. 1.38.5; cf. Frazer 1898, 502. If so, Plato may have expected some readers to be familiar with the legend that this was the spot where Hades returned to the underworld with Persephone. The nature of such a suggestion will not seem far-fetched to anyone who recalls Phdr. 229b-c. 
are likely to have known this independently) that the historical situation depicted in the dialogue's introduction was the occasion of Theaetetus's death. ${ }^{2}$ Obviously telling in this regard is Euclides' description of how, when he came across Theaetetus being carried along, he found him 'alive, but only barely so', and suffering from debilitating dysentery as well as his wounds (142b). In the dialogue's 'real time', then, as Euclides and Terpsion listen to the reenactment of an episode from Theaetetus's adolescence, Theaetetus the man is dying: the talented young mathematician lives again in the (philosophical) imagination, preserved in Euclides' and/or Plato's text, even as his adult self as citizen-soldier brings about his destruction. But does the juxtaposition of Theaetetus's youthful promise with his fatal wounds and sickness (and his desperate need to get home, 142c2) cast a retrospective poignancy over his life? Or does it, instead, allow a kind of philosophical redemption or 'overcoming' of his death? In this and the other respects I have mentioned, the introduction of the dialogue has a potential significance which 'spills', as it were, over the framework of its own literary form and creates for its readers opportunities for reflection (on the imagined lives of Socrates, Theaetetus, Euclides, and Terpsion) which are not susceptible of theoretically neat definition. ${ }^{3}$

I have chosen a few details from the start of the Theaetetus as a convenient way of highlighting questions of narrative form and significance which are of much wider consequence for the reading of the Platonic dialogues. In the context of a collective project on the value of narratology for the interpretation of ancient texts, the particular interest of Plato stems from a combination of two circumstances. One is the fact that in the well-known stretch of Republic Book 3 (392c-8b) where Socrates, with some rather faltering help from Adeimantus, proposes a set of principles with which to analyse and evaluate poetic lexis (here signifying the presentational form or mode of discourse, $\log o s)$, narratologists have been prepared to identify at least an embryonic 'theory of narrative' and the earliest known ancestor of their own critical methods. ${ }^{4}$

2 The dramatic date is probably 391 rather than 369: see Nails 2002, 274-8, $320-1$.

3 For further discussion of the dialogue's frame, with emphasis on the way in which it suppresses an authorial explanation on Plato's part (producing a 'narratological asymmetry' between him and Euclides), see Morgan 2003.

4 Lexis should not here be translated as 'diction' (i. e. word choice), contra e.g. Shorey 1937, 225 etc., Morgan, K. 2004, 358; Bers 1997, 13 blurs the point. Note the conjunction and virtual synonymy of lexis and diêgêsis at 
The other is the far more diffuse fact that Plato's own procedures as a writer make extensive and, as we have already glimpsed, elaborate use of various types of narrative structure, thus prompting questions about the relationship between narrative theory and practice in the dialogues. Can we use the 'theory' advanced by Socrates in Republic 3 (and said by him, as we shall see, to be applicable to more than poetry) to test Platonic writing itself? If so, with what results? If not, why not? One of my goals in the present chapter is to suggest that both separately and in combination these two circumstances - the 'embryonic narratology' of Republic 392c-8b, and the narrative self-consciousness of Plato's own writing - are more difficult to assess than is sometimes appreciated. The nature of this difficulty can throw light on issues which remain worth the consideration of anyone concerned with theoretical models of narrative, as well as being of basic importance for the reading of Plato's work itself.

Before embarking on a close reexamination of Republic 392c-8b, it may be helpful to provide some preliminary orientation. First of all, a warning about terminology, though one with conceptual implications as well. Throughout my discussion, unless otherwise signalled, I shall employ 'narrative' to designate what Plato's text, at 392d and subsequently, ${ }^{5}$ treats as the genus diêgêsis, roughly equivalent to temporally plotted discourse. This means, among other things, that I diverge from the common modern practice of equating 'diegesis' with what Socrates counts at $392 \mathrm{~d}$ as one particular species of that genus, i.e.

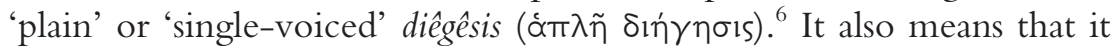

396b11; at 396c6 lexis is used more loosely to denote 'speech' or 'utterance' as opposed to action (cf. 5.473a). For narratological responses to R. 392c ff., see e.g. Genette (1972) 1980, 162-73, de Jong (1987) 2004, 2-5, Laird 1999, $48-78$.

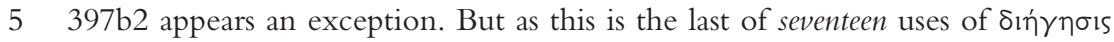
and cognates at $392 \mathrm{~d}-7 \mathrm{~b}$ and is out of line with the preceding sixteen, there is a case for emendation (with addition of either $\alpha \pi \lambda \tilde{\eta} s$ or ${ }^{\prime} \alpha \lambda \eta \eta$ s: for the latter cf. 396e6, where Adam unnecessarily emends to $\propto \pi \lambda \tilde{\eta}$ s). 397a2, where the main mss. have $\delta ı \gamma \eta \dot{\sigma \varepsilon} \propto$, need not be an exception to the generic sense: on the logic of the sentence, see Slings 2005, 47.

6 Modern narratological usage of 'diêgêsis' etc. has, of course, several variants, complicated by the French distinction between 'diégèse' and 'diégésis': see e.g. Genette (1983) 1988, 17-18. But it remains an error to use 'diegesis' tout court for one species rather than the genus when paraphrasing $R$. 392c4c, as do (among many) Chatman 1974-5, 312, Prince 1988, 52, s.v. 'mimesis', Genette (1972) 1980, 164, Murray 1996, 168, Bers 1997, 11. Cf. Kirby 1991, 
is not here a requirement of 'narrative' (or diêgêsis) per se that it should have a 'narrator': in the terms of Socrates' classification, drama is itself a species of narrative/diêgêsis, i. e. wholly mimetic diêgêsis (cf. 394c1). My present terminological usage is intended to maximise a scrupulous attention to the details of this section of the Republic and thereby to assist in drawing out both the subtleties and the problematic features of the argument. In pursuing this aim, I shall attempt to develop the following four lines of thought, all of which could profitably be taken further than I have the space to do here.

(1) If there is anything like a 'theory of narrative' to be found at Republic $392 \mathrm{c}-8 \mathrm{~b}$, it is itself necessarily embedded in the practice of Platonic writing: i. e., it is a representation of the joint efforts of Socrates and Adeimantus to arrive at such a theory. Since, in my view, there is no reliable hermeneutic for tracing a monologic authorial stance (about anything) within Platonic dialogue, 'theory' and 'practice' of narrative in Plato are therefore - here and elsewhere - inextricable. This means, more specifically, that one should not extract a conception of narrative from the text and treat it as though it had independent, free-standing Platonic authority. I shall adhere closely to this injunction in what follows, a procedure which distinguishes my approach from most existing treatments of the subject.

(2) In the passage of Republic 3 in question, Socrates' classification of the formal possibilities of narrative is more intricate and in some respects uncertain than is often realised; it calls for careful, cautious explication. In particular, I shall contend that the tripartite typology of lexis at 392c-4c - which divides the genus 'narrative' (diêgêsis) into two main forms, 'plain' (or 'single-voiced') and 'mimetic'

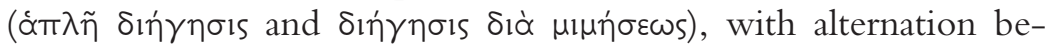
tween the two constituting a third, compound form (literally narra-

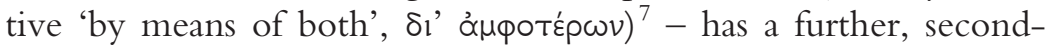
order and normative typology overlaid on it at $394 \mathrm{~d}-8 \mathrm{~b}$. This produces considerable convolutions in the scope of the supposed 'theory' contained in the text.

118. In Halliwell 2002, 54 n. 42 an unfortunate misprint has omitted the word 'not' before 'equivalent'.

7 Plain or single-voiced narrative (for the translation of $\propto \pi \lambda \tilde{\eta}$ cf. n. 17 below): 392d, 393d, 394b. Mimetic narrative: 392d, 393c, 394c-d, etc.; this mode is

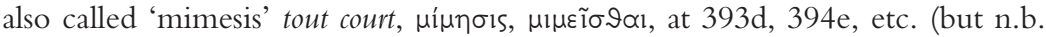
the wider sense of mimesis earlier in Book 2, at 373b: cf. Halliwell 2002, 51 n. 35). Compound narrative: 392d, 394c, 396e. 
(3) The ramifications of 392c-8b are complicated further when we read this section in the light of the lengthy preceding discussion (at 2.376e-3.392c) of the kinds of poetic stories or discourses (muthoi, 'stories' or 'myths', being treated, broadly speaking, as 'false' and/

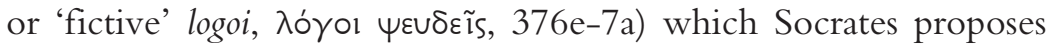
as (un)suitable for the education of the Guardians of the ideal city under imaginative construction. If it is justifiable to find at least an emergent 'theory of narrative' at Republic 392c-8b, that theory ought to count, then, as part of a larger (though, as I shall stress, incomplete) 'theory of discourse' as adumbrated at 376e-98b. But there are a number of difficulties in the relationship between these two stages of argument, difficulties which have received insufficient attention in the scholarly literature but which affect the boundaries of the concept of 'narrative' itself and involve a less than fully integrated dialectic between different ways of interpreting the meaning(s) of narrative texts. Although I shall touch further on this side of the architecture of the dialogue in the later parts of my paper, its implications should be borne in mind throughout.

(4) Any attempt to use Republic 392c-8b (even more so, 376e-398b) as the source of criteria with which to frame an assessment of Plato's own practice as a writer needs to face up to several stiff challenges. In addition to the fundamental consideration (see [1] above) that this passage of Book 3, whatever its theoretical possibilities, is itself part of the practice of Platonic writing, these challenges include what I hope to show is the significant fact that Socrates' primary schema of plain, mimetic and compound diêgêsis, though used later in antiquity to produce classifications of Platonic dialogue form, ${ }^{8}$ is insufficient to cope with the degree of diegetic variety found in Platonic writing and therefore cannot be taken as a comprehensive or definitive typology.

8 The classifications in question (there were others too, but based on different cri-

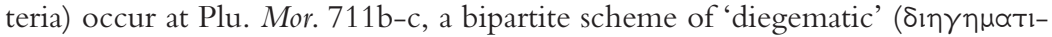
kós, i. e. introduced by what $R$. 392d calls $\propto \dot{\pi} \pi \lambda \tilde{\eta} \delta ı \dot{\gamma} \eta \sigma 1 s)$ and 'dramatic' works; D. L. 3.50, a tripartite scheme of 'dramatic', 'diegematic', and 'mixed' ( $\delta \rho \alpha \mu \alpha-$

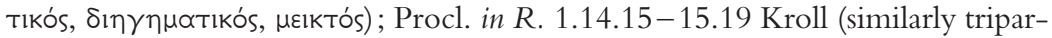

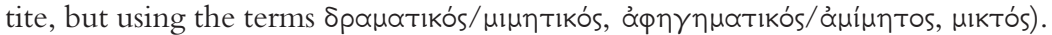
For the broader adaptation and extension of these formal categories in ancient criticism, see Haslam 1972, 20-1, Janko 1984, 128-30. 
Having given this overview of the direction of my argument, I turn first to some of the problems raised by Socrates' classification of poetic (and, more obliquely, prose) lexis into plain, mimetic and compound forms or species of diêgêsis. As I proceed, I will use these problems as a reference point for some comparisons with Plato's own wider practices in the dialogues. It will be clear from what has already been said that my approach makes it imperative to refer to 'Plato' only as author of the text and to avoid the question-begging though standard procedure - 'Plato argues', 'Plato supposes', etc. - of treating him as though he were himself an omnipresent voice audible within the dialogue.

The typology of lexis put forward by Socrates at 392c-4c addresses 'narrative' in a conceptually broad rather than a formally narrow sense. The term diêgêsis (and equivalently, though only in passing as it were, the noun ơ $\pi \propto \gamma \gamma \varepsilon \lambda \dot{\alpha} \alpha$, literally 'reporting', and the verb ó $\left.\pi \propto \gamma \gamma \gamma^{\prime} \lambda \lambda \varepsilon \varepsilon v\right)^{9}$ is used to denote narrative in this broad, generic sense as discourse keyed to a temporal framework of events: 'is it not the case that everything said by storytellers or poets is narrative of past, present or future

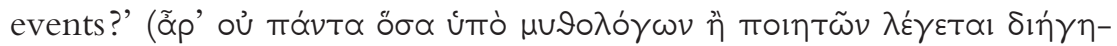

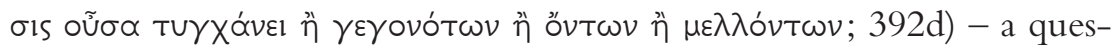
tion, we need to note for future reference, which indicates that the analysis applies to narrative in prose as well as verse. ${ }^{10}$ It is important that in dividing the genus diêgêsis into single-voiced, mimetic and compound forms, Socrates defines the first of these not as third-person narrative without qualification but as comprising utterances by 'the poet himself (393a-d, etc.). The account of Chryses' first approach to the leaders of the Greek army at Iliad 1.12-16 is a case in point: in these lines, on

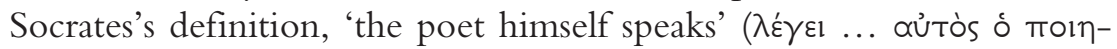
tท́s, 393a). By automatically equating a (primary or work-framing) third-person narrative with the voice of the poet, Socrates might seem to be sustaining a premise of authoriality which was active in

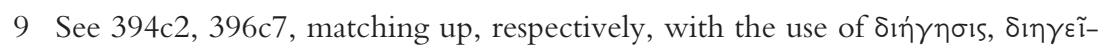

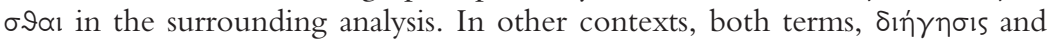
๙̊ma $\gamma \gamma \varepsilon \lambda i \alpha$, could easily refer to third-person narrative alone, but Socrates is not following general usage (hence Adeimantus's uncertainty at 392d).

10 See $378 \mathrm{c}-\mathrm{d}$ for a further indication that the critique as a whole, and therefore implicitly the analysis of lexis, applies also to prose (oral) storytelling;

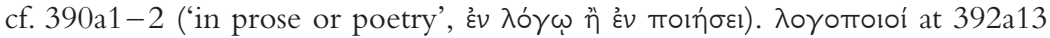
also probably refers to prose-writers, despite the application of the related verb to poets themselves at 392a. See my text below for the broadest indication of all, at $397 \mathrm{c}$, that the principles at stake are not confined to poetry. 
the earlier part of the critique of poetry, i. e. the broader discussion of discourse at $2.376 \mathrm{e}-3.392 \mathrm{c}$, where formulations of the type 'the poet says' were used in paraphrasing passages from Homeric and other texts. But I shall argue later that there is a difference between that earlier premise - which is a global and supra-textual principle of ethical responsibility for the expressive content of poetic works - and the present, intra-textual definition of the plain or third-person narrative mode as communication in the voice of 'the poet himself': hence the fact that in the earlier stages of the discussion, as we shall see, formulations of the type 'the poet says' were not restricted to passages covered by Book 3's definition of plain or single-voiced narrative. Moreover, that definition itself conspicuously ignores the possibility (formally recognised, according to some scholars, in Aristotle's Poetics) ${ }^{11}$ of a primary narrator who is neither a character in the narrative nor the author of the work. As it happens, that possibility is one which is never found in Plato's own dialogues; but then nor is the 'author-as-narrator' type which for Socrates is paradigmatically exemplified by Homeric epic. In this latter respect, it looks as though Plato, unlike Xenophon, deliberately shields his work from being read as direct authorial testimony. ${ }^{12}$ Platonic dialogues with a framing narrative in 'compound' mode (there is no instance of a frame entirely in 'plain' mode) always ascribe the role of primary narrator to an identifiable individual, either Socrates himself (Charmides, Lysis, Republic) or someone else (Cephalus in Parmenides).$^{13}$ But that last point can in turn be converted back into a further observation on Socrates' typology: namely, that it makes no allowance for works

11 See de Jong (1987) 2004, 5-8 and (somewhat differently) Lattmann 2005, esp. 36-43, 46-7, on Arist. Po. 3.1448a21-3, 23.1460a5-11: interpretation of both these passages, however, remains vexed.

12 Cf. Morgan, K. 2004, 359: 'The Platonic narrator is never Plato'. Xen. Mem., Oec. and Smp. all begin with direct first-person statements which invite ascription to the author himself; in the second and third of these works there are also claims (however historically questionable) of eye-witness testimony. Plato's presence at Socrates' trial, inserted as a 'dramatic' detail at Ap. 34a, 38b (overlooked by Morgan ibid.), is obviously a different literary procedure altogether; cf. the pointed reference to his absence from Socrates' death-bed scene at Phd. 59b.

13 Morgan, K. 2004, 364 wrongly counts the Symposium as having a 'narrative' rather than 'dialogical' frame, but then (365) refers to its 'opening conversation' (cf. her n. 16, which obscures the point). Vegetti 2007, 457 n. 42 wrongly describes the Republic itself as 'la mimesis di una diegesis socratica': in the terms of $R$. 392d, it is, of course, a compound diêgêsis. 
framed by narratives in the voice of a character either involved directly in the events narrated (as with the Republic itself) or reporting an account derived from other persons so involved (Cephalus in Parmenides being a sort of halfway house between these two things). ${ }^{14}$

Despite its apparent claim (392d) to be applicable to narrative discourse in general, then, Socrates' typology is not only incomplete (ignoring three of the four main kinds of primary narrator, i.e. every kind other than the author-as-narrator type) but also doubly out of alignment with Plato's own practice in this regard. It puts heavy emphasis on a category (the author-as-narrator) which is not found in Plato's texts, and at the same time it fails to encompass practices of narrative framing which Platonic dialogues do exploit. So the typology is far from comprehensive, and Plato could hardly have thought that it was. This limitation is obviously in part a consequence of the fact that the typology is slanted towards a particular purpose, evaluation of the narrative forms or modes employed in two main kinds of Greek poetry, Homeric epic (and early hexameter poetry in general) and Attic drama: these are the only genres from which quotations are taken in this stretch of the dialogue. ${ }^{15}$ It is true that 394 c shows that Socrates intends the typology to be applicable to existing poetry more broadly, not just to epic and drama: he says that cases of unvarying, single-voiced narrative (here again equated with the voice of 'the poet himself) are exemplified 'especially in dithyramb', and that the compound mode occurs 'in many other places' (presumably including narrative elegy) as well as in epic. ${ }^{16}$ But the absence of direct examples of any poetry

14 Contrary to what is sometimes said, e. g. by de Jong - Nünlist 2004, 545), there is no case of a Platonic dialogue framed by a 'narrative' (i.e. either plain or compound diêgêsis, as opposed to a framing conversation) in the voice of a 'disciple' of Socrates who himself either participated in or witnessed the recalled dialogue. Parmenides fails this test twice over: the primary narrator was not present at the main dialogue recalled, and Cephalus is not in any case a disciple of Socrates.

15 The only genres quoted at any point in the critique, in fact, are 'epic' hexameters (including the unknown verse at $379 \mathrm{e} 2$ and Hesiod fr. [dub.] $361 \mathrm{M}-\mathrm{W}$ at 390e3) and tragedy.

16 As regards dithyramb, Socrates can be taken to be referring both to the predominant use of 'plain' narrative for the telling of myths and to the general prominence of the poet's first-person voice (e.g. in invocations to the Muses or in other self-conscious comments on the performance of song): both features can be seen in the fragments of Pindar's dithyrambs. But elements of mimetic speech were found in at least some 'modern' dithyrambs: see Timotheus Persae 
other than epic and drama in the course of $392 \mathrm{c}-8 \mathrm{~b}$ leaves no doubt about the dominant focus of the discussion and helps to account for the corresponding simplification of the scheme. That does not, of course, make the poet-narrator model of third-person narrative uncontroversial even for Homer, though Socrates makes it sound as if it were. One could press this point in either (or perhaps both) of two ways: one, which is not really my concern here, by comparing Socrates' procedure with wider Greek cultural assumptions about the poet's presence in his work; the other, which I have already touched on and will return to later, by trying to correlate Socrates' emphasis with the larger understanding of authorial responsibility which can be tracked in the critique of poetic discourse (logoi) from 376e onwards. But whichever of those strategies one adopts, one must also recognise that Socrates' interpretation of plain or single-voiced narrative (used either alone or within the compound mode) as essentially a vehicle of authorial 'speech' is not adequate to cope with all the varieties or nuances of narrative presentation, including those employed in the Republic itself. In fact, we can say that his explication of $\propto \pi \lambda \lambda \tilde{\eta} \delta i \eta$ ' $\gamma \eta \mathbf{s}$ is designed above all to stamp it as 'single-viewpoint' narrative, ${ }^{17}$ thereby suppressing the various ways (only too familiar to Plato himself as writer) in which non-mimetic narrative can achieve more complicated effects of perspective than are easily attributable to a unitary authorial voice. But this suppression serves a larger purpose, as will become clear later on, in relation to the overall concern of the argument with the dangers of psychic multiplicity in poetry.

These considerations can be reinforced by examining the other major component of Socrates' typology, 'narrative through mimesis'

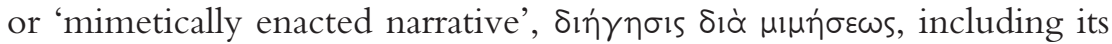
contribution to the compound mode. Socrates defines mimetic narrative in terms of the direct representation of character speech: the agents' 'spoken words', ṕñعıs (393b, 394b), and the 'exchanges' or dialogue (åmoı $\beta \propto \tilde{\imath} \alpha, 394 b)$ between them. ${ }^{18}$ It is not without significance, how-

791 col. iv.150-61 PMG, Scylla 793 PMG (registered in Aristotle's complaint about Odysseus's lament, Po. 15.1454a29-31), and cf. ps.-Arist. Probl. 19.15, $918 \mathrm{~b} 18-19$. Note also the possibility of a connection with dithyramb in Socrates' later complaints about highly 'mimetic' music at 397a: cf. Zimmermann 1992, 123-4, Hordern 2002, 38-9.

17 Part of the force of $\propto \pi \lambda \tilde{\eta}$, 'plain' or 'single', in the nomenclature of the typology depends precisely on a contrast with the 'double' ( $\delta 1 \pi \lambda \circ u \tilde{s})$ or 'multiple' ( $\pi \circ \lambda \lambda \propto \pi \lambda$ oũs) voices of mimesis: see esp. 397e; cf. de Jong (1987) 2004, 3-4.

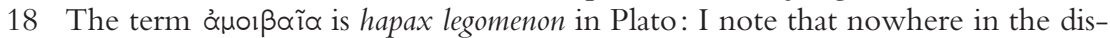
cussion of poetry in $R$. Books $2-3$ do we find the regular terms for conversa- 
ever, that here too he preserves traces of an authorial presence by making the poet 'speak $a s^{\prime}$, or take on the guise of, each character. ${ }^{19}$ Once again, Socrates' construal of his categories is designed to cope with the kinds of poetry on which his sights are chiefly fixed; so wholly mimetic narrative, unsurprisingly, is drama (394b-c), while compound narrative is principally epic. If the exposition of these formal options seems deliberately rudimentary, that is in part for dramatic reasons: Socrates, like a schoolteacher, is guiding an Adeimantus who has some difficulty grasping the essentials (392d). But in treating Homeric epic as comprising a framework of author-narrative which introduces and separates a sequence of character speeches (392e-3c), Socrates creates the impression that at any particular juncture plain and mimetic narrative are either-or and exhaustive alternatives. This means that at the level of classification he disregards, among other things, the degree of formal (and more than formal) narrative intricacy which arises with an embedded story on the scale of Odysseus's Phaeacian apologos in Odyssey 9-12, even though that part of the epic was cited several times for other purposes earlier in Republic 3 itself. ${ }^{20}$ In the case of the Phaeacian narrative the voice of a character becomes so sustained as in effect, on Socrates' terms, to displace 'the poet himself as the controlling narrator. What's more, contained within this supplementary or secondary narrative framework are numerous speeches on the part both of Odysseus himself and of other characters he interacts with or encounters. At two points, in addition, we are given the speeches of characters in narratives embedded at one further remove within Odysseus's story, reporting occasions on which Odysseus himself was not present: the speech of Poseidon to Tyro at Odyssey 11.248-52, where Odysseus momentarily functions

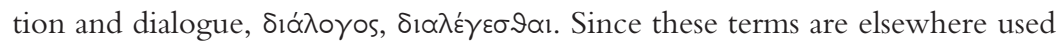
for Socratic dialogue itself (e.g. R. 1.336b, 354b), and therefore by implication for the dominant form of Plato's own writings, this avoidance tacitly masks the relationship between Socrates' taxonomy and the work in which it appears.

19 See the various formulations at 393a ff.: they cluster round the idea of the poet speaking 'as someone else', ஸ́s ö $\lambda \lambda$ os tis vel sim.

20 See 386c (Achilles' notorious words of disillusionment in Hades, here 'deleted' or censored yet quoted again by Socrates at 7.516d!), 386d, 390a-b (twice). Quotations from and allusions to Odyssey 9-12, especially the 'Nekyia', occur in several other Platonic works: for their importance in the early sections of Protagoras, see Segvic 2006, though at 248 she gives a simplified compression of the thesis of Halliwell 2000. 
as an 'omniscient' narrator, ${ }^{21}$ and the exchange between Helios and Zeus at 12.377-88, for which Odysseus quotes his source (see below). The general consequence of Socrates' silence about such things is that he effectively screens out the possible multiplicities of layering in which narrative voices can be inserted. Yet it is not immediately easy to see why he should underestimate the intricate variations of mimetic and compound narrative forms, since the anxieties he will go on to express about these forms at 393c ff. will centre precisely on discursive multiplicity and its implications for the soul. We shall therefore have to keep this question in mind when we reach that ensuing stage of the discussion.

Before that, it is worth underlining that Socrates' omissions or silences as regard the possible complexities of narrative form happen to stand in an interesting relationship, once again, to the practices of Plato's own writing. The position of Odysseus within his apologos to Alcinous is closely comparable to that of Socrates himself in the Republic. ${ }^{22}$ Both Odysseus and Socrates, as 'internal' narrators, present elaborate accounts within which they quote both their own and others' direct speech. Both, moreover, include subordinate narratives at one remove. In the Republic, indeed, Socrates does this to a greater extent than Odysseus and with a wider range of variant techniques. Occasionally this may reflect relatively ordinary conversational chains of transmission: Socrates reporting Cephalus quoting the aging Sophocles' witty rejoinder about his quiescent libido (329b-c) perhaps falls under this heading (which is not to deny that the passage has a larger resonance for the themes of the dialogue). But the complexity of the narrative form of the Republic, and the consequent layering of Socrates' voice as narrator, goes much further than that. One example of this is the long speech early in Book 2 in which Adeimantus sets his own statements in a sort of counterpoint with the direct speech of more than one hypothetical interlocutor (imagined, furthermore, in conversation with both self

21 Note here that the function of 'omniscient narrator' has no place in Plato's own dialogues. Morgan, K. 2004, 363-4 is misleading on this point: her examples illustrate Socrates' strong readings of others' behaviour/psychology, but nothing which 'borders on omniscience'.

22 Socrates invokes the apologos ironically as an anti-model for the myth of Er at $614 \mathrm{~b}$ : this is the very point, of course, at which Socrates ceases to be an Odysseus-like internal narrator. On larger thematic comparisons/contrasts (beyond my scope here) between the Platonic Socrates and Odysseus, cf. Hobbs 2000, esp. 195-6, 239-40. 
and others, 365b-6b), and also repeats to Socrates, as a composite 'quotation', the sentiments which Adeimantus and Glaucon had previously put to their mentor (366d-7a): so in this last passage, by a kind of narrative loop, Socrates (as primary narrator) is quoting Adeimantus in the act of quoting Adeimantus himself back to Socrates. (Whose voice, let alone whose point of view, are we hearing in such a context? The question admits no stable answer.) Other examples of the Republic's narrative complexity include Glaucon's recounting of the fable of Gyges' ring at $2.359 \mathrm{c}-60 \mathrm{~b}$; the extemporised speech which Socrates imagines himself making to the citizens of Callipolis as part of the myth or story (muthos) of the so-called 'noble lie' (3.415a-c); the passage of Book 5 where Socrates overlays on his (reported) conversation with Glaucon an imaginary conversation with a 'lover of sights and sounds' who denies their view of beauty, in the process producing a kind of blurring of voices which resists clear-cut formal analysis; ${ }^{23}$ and the section of Book 8 where Socrates begins his account of defective constitutions by positing a quasi-Homeric invocation to the Muses and then conjecturing their reply in lengthy direct speech (545d-7b).

These examples illustrate the layered multiplication of voices which sometimes occurs within the narrated dialogue (i.e. the compound diêgêsis) of the Republic itself. ${ }^{24}$ Even so, they do not represent the work's full range of narrative techniques, which encompass also the myth of Er's extraordinarily extended oratio obliqua (an option not given any prominence in Book 3's taxonomy of lexis), embedded in which are further diegetic variations, including indirect discourse 'nested' within indirect discourse. ${ }^{25}$ But if such formal intricacies partly parallel some

23 476e ff. The blurring occurs when the conversation, after starting with Glaucon playing the part of the imaginary interlocutor, becomes indistinguishable from an exchange between Socrates and Glaucon themselves; the difference between the two conversations is eventually reasserted at $479 \mathrm{a}$, but it then becomes blurred again in the same way as before, and there is no further reference to the hypothetical interlocutor.

24 Some examples of narrative complexity in other dialogues are documented in the interesting treatment of secondary and embedded narratives in Morgan, K. 2004, 368-76.

25 The myth of Er is framed in what I would call foregrounded oratio obliqua, as opposed to the 'background' oratio obliqua of, say, the Symposium: cf. Halliwell 2007, 449-50, with Tarrant 1955 for a useful conspectus of sustained passages of indirect speech in Plato. The myth of Er's framework incorporates direct speech (615d-16a, 617d-e), nested indirect speech (614d, 619b, 620d), nested 
of the practices of Homeric narrative omitted by Socrates' typology, there is another, somewhat different point of contact between one part of Odysseus's apologos and the nature of Plato's own writing. Odysseus explains that his version of the conversation between Helios and Zeus is derived from information given him by Calypso, who had heard it in turn from Hermes. One need not broach here the larger issues raised by the functions of human and divine narrators in the Odyssey in order to notice that this provides a precedent for the way in which, in works like Parmenides, Symposium and Theaetetus, Platonic narrators draw attention to the multiple stages through which their accounts have reached them from other sources. Taking all these factors into consideration, then, we come back round to the striking but usually overlooked conclusion that the variants omitted from Socrates' typology of diegetic lexis happen to coincide to a considerable degree with narrative possibilities and complications exploited in Plato's own work. Despite its stated applicability to narrative discourse in general, the typology of diêgêsis renders the operations of Platonic writing itself anything but transparent. ${ }^{26}$

I would like here to comment briefly on a further aspect of the asymmetry between Book 3's typology and Plato's own writerly practices. This concerns what we call Platonic 'myth', including the Republic's own myth of Er as well as, arguably, such passages as the Cave analogy. I mentioned just above some of the intricacies of narrative form which can be found in Platonic myths, but there is a broader comparative observation which deserves to be added. Socrates' diegetic typology, and indeed his entire critique of poetry in Books $2-3$, uses the vocabulary

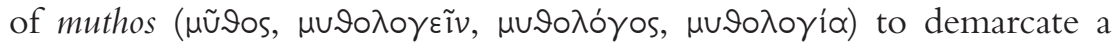
corpus of narrative material and a set of mythologic activities which the ideal city would need to regulate. The same terminology is often, though not invariably, found in Plato to describe those passages which are now typically classified as Platonic myths: the myth of Er is a case in point $(10.621 \mathrm{~b} 8)$. Socrates' discussion in Republic $2-3$ treats

free indirect discourse (619c), and intruded commentary by Socrates (616d, 618b-19a, 619d-e).

26 See, however, the shrewd but I think inconclusive attempt of Blondell 2002, 232-45 to argue that the Republic itself does (partly) practise what Socrates preaches about mimesis in Book 3. 
muthoi as narrative or discursive units (a subset of logoi: $2.376 \mathrm{e})^{27}$ in their own right, but it makes no allowance for muthoi which occupy a place within a larger discursive or textual context. It is true that Socrates acknowledges the existence of external (i. e. social) contexts or occasions of performance: in particular, the recounting of myths by adults to children in early upbringing (esp. $2.378 \mathrm{c}-\mathrm{d}$ ), the general learning and assimilation of poetry within an educational framework, and the recitation/ acting of epic and drama within institutional settings. ${ }^{28}$ But he nowhere indicates that an act of 'myth-telling' ( $\mu$ $\vartheta \circ \lambda \circ \gamma i \alpha$ ), rather than being a free-standing or self-contained text/performance, might itself be part of a larger discourse. Yet this is always the status of myth-telling in Plato's own works. All Platonic myths are speech acts (and perhaps 'speech genres' too) which occur within a larger, overarching framework of dialogue. Whatever else one makes of any passage of muthologia in the dialogues, it must matter that each instance is positioned within such a framework: it is told by the voice of a particular speaker to a particular audience, at a particular juncture in a discussion, for particular (though not necessarily self-evident) reasons. In short, muthologia within Plato's own writing always has more than discrete narrative 'content' and 'form': it is also partly constituted by the discursive circumstances or conditions in which it is presented. Yet Socrates' typology in Republic 3 , precisely by focussing analytically on seemingly self-contained features of narrative structures, obscures the possible importance of such larger circumstances. Where poetry is concerned, this seems not to matter to Socrates' method, since he proceeds on the assumption (signalled at $377 \mathrm{c}-\mathrm{d}$ ) that everything is equally muthos. But that does not alter the fact that if one compares Socrates' procedure and assumptions with $\mathrm{Pla}-$ to's own general practices as writer, one is struck by a fundamental gap between the two. The Platonic Socrates remains silent about some of the very things which are most distinctive of the work of his own author.

27 Contrast e.g. Phd. 61b for the idea of poetry as quintessentially muthoi rather than logoi: on fluctuating Platonic formulations of the relationship between $m u$ thos and logos, cf. Halliwell 2007, 452-5.

28 The discussion in Book 3 leaves the nature of such institutions within Callipolis somewhat vague. But organised recitation/performance by the young Guardians is clearly if cautiously presupposed at 3.395b-6e (note the use of ṕtwp, 396e10, for 'public reciter'); cf. Halliwell 2002, 52 n. 37. Burnyeat 1999, 271-3, with some strain, thinks Socrates' concern is more with the writing than the performing of plays. 
If the incompleteness of the tripartite schema developed by Socrates at $392 \mathrm{c}-4 \mathrm{c}$ creates more than one possible conundrum for readers of Plato's text, another set of interpretative challenges is introduced by the fact that what initially looks like a formally or technically descriptive typology turns into a set of psychologically and ethically normative principles. An alternative formulation of this point is to say that at $394 \mathrm{~d}-8 \mathrm{~b}$ Socrates starts to superimpose a second-order typology of discursive form, lexis, onto his first-order typology. ${ }^{29}$ One preliminary observation worth making on the transition which starts at 394d (and which, in the larger scheme of $376 \mathrm{e}-98 \mathrm{~b}$, is actually a reassertion of the normative over the descriptive) is that Socrates professes to be uncertain where the argument might lead: 'I myself really don't yet know [sc. everything that is at stake], but we must go in whatever direction the argument, like a wind, may carry us' (394d). This uncertainty is the sort of detail many Platonic scholars treat as a frill (if they notice it at all). But those convinced that there are no frills in Plato will be inclined to take it as a dramatic cue to recognise that any attempt to prescribe a set of principles for the relationship between discursive content and

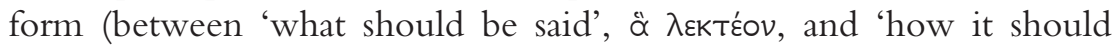

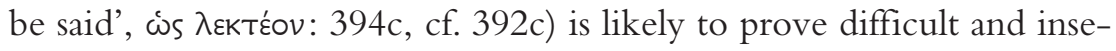
cure.

One thing seems clear enough, however. Socrates' concern with 'form' revolves around what he sees as the intrinsic potential of mimesis (qua dramatised narrative or the use of direct discourse) to induce psychic multiplicity. As soon as he poses the question whether the Guardians in

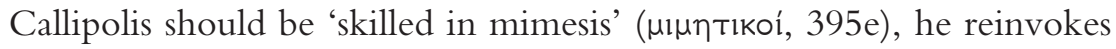
his earlier principle that each of them needs 'to practise one thing well, not many things'; and the quadruple repetition of то $\lambda \lambda \lambda_{\alpha}$, 'many things', at $394 \mathrm{e}-5 \mathrm{~b}$ establishes the thematic note emphatically. It is true that Socrates risks confusing matters by stressing that even particular species of mimesis (such as tragedy and comedy) are, from the point of view of poets and performers, separate practices; the same person, he thinks, cannot be good at more than one of them (395a). But it soon becomes evident that it is psychological multiplicity as a consequence of engage-

29 Cf. Giuliano 2005, 43-58 for an alternative analysis of the stages of argument at $392 \mathrm{c}-8 \mathrm{~b}$; he finds a more tightly interlocked chain of reasoning than I do, as well as a more straightforward match with Plato's own writing. 
ment in unrestricted mimesis which lies at the heart of his anxieties. ${ }^{30}$ If we focus on the argument's immediate extrapolations from its typology of narrative form, what seems most pertinent is that Socrates takes every mimetic utterance, unlike cases of plain or single-voiced narrative, to involve strong psychological assimilation to another mind - first on the part of the imaginatively creating poet (see esp. 393c), then on that of the performer or 'reciter', though this part of Republic 3 stops short of extrapolating all the way to the experience of audiences of poetry. The argument therefore entails that different narrative forms are not simply technical alternatives for the telling or presentation of stories: for Socrates, they have differential expressive capacities to embody the points of view and mental processes of agents or characters in the story. The crux of the matter here can be exposed by glancing back at Socrates' brief illustration of how to rewrite the early stages of the Iliad (1.12-42) into 'plain narrative', stripping it of all mimesis (393d$4 a)$. If we think of narrative point of view purely in terms of 'information' about individuals' reactions, it is unclear why plain narrative cannot in principle achieve the same effects as mimesis. ${ }^{31}$ Socrates' short example does, after all, convey information about the viewpoints of the agents - Chryses' fear (before and after his request for the return of Chryseis), the respect felt for the Trojan priest by the Greek army/leaders as a collective unit, and the anger of Agamemnon - both through narrative statement and through (free) indirect discourse. ${ }^{32}$ What's more, Socrates stresses the cursory, 'unpoetic' nature of the illustration, leaving us free to imagine (or remember) how much more elaborate and powerful the use of 'plain narrative' might be in the hands of a real poet

30 For a larger perspective on this point and its implications for the role of imagination in aesthetic experience, see Halliwell 2002, 72-97. I cannot accept the claim of Brisson 1998, 69-70 that Book 3's critique deems mimesis 'intolerable' on grounds of 'illusion' or of 'confusion ... between reality and discourse'.

31 Genette (1972) 1980, 166 is misled by Socrates' illustration into equating mimesis with 'maximum of information' and (plain) diêgêsis with the opposite; but there can be no necessary correlation between the two modes and the quantity of information conveyed: it is easy to find examples of 'informationally' thin direct speech and richly detailed single-voiced narrative. Bal (1985) 1997, 37, perhaps influenced by Genette in this respect, garbles the point of Socrates' illustration.

32 Narrower usage of 'free indirect discourse' implies absence of speech tags ('he said' etc.): that would not apply to most of Socrates' rewriting of the passage.

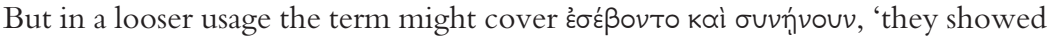
him respect and approval', which corresponds to the indirect discourse of Il. 1.22-3. On the scope of 'free indirect discourse', cf. Prince 1988, 34-5. 
(or, equally, of a fine prose writer). Agamemnon's abuse of Chryses is presumably an instance of the sort of behaviour Socrates does not want to be offered to the young Guardians of Callipolis in mimetic narrative. Yet he seems happy to think of them having an account of it in plain narrative: the 'de-mimeticised' version preserves the king's threat of violence (including scorn for Chryses' priestly office) and an indication, admittedly less explicit than in Homer, of Chryseis's future as a concubine. Why then in principle should there be such a big difference between the two narrative modes?

Socrates' answer is that mimesis is habit- and character-forming (395d), because for poets and actors at least it is a kind of enactment that shapes the soul and the self on the 'inside'. The same is not true, he supposes, of plain narrative, presumably because even for a reciter or performer of such passages there remains a psychological distance from the characters, who are described and as it were observed, not impersonated or internalised. Part of the underpinning of this position is a larger thesis about the 'developmental psychology', so to speak, of childhood and early adulthood: an important philosophical issue in its own right but one which must be left aside here. In any case, Socrates noted at several points in the first part of the critique of poetry $(378 \mathrm{~d}$, 380c, 387b) that his case does not apply exclusively to children, and this ought to hold good for the discussion of narrative form as well. But we need now to confront the often neglected fact that Socrates' view of mimesis has two sides to it which do not stand in an entirely fixed or static relationship. On the one hand, he sees mimesis (again, principally from the point of view of actors or reciters) as an especially potent form of narrative in the immediacy of its impact and the directness of the psychological assimilation (or self-likening, 393c) which it involves: in this regard, mimesis induces the mind to 'mould' itself (a Gorgianic trope) into a particular identity. ${ }^{33}$ But Socrates also dwells on the tendency of mimesis to multiply narrative voices and thereby to encourage fragmentation of the soul/self. The first of these aspects, as Socrates appreciates, is ethically ambiguous: where 'good' characters (i.e. good role-models for the Guardians) are concerned, the power of mimesis is positively valuable. But a core concern for unity of soul makes the

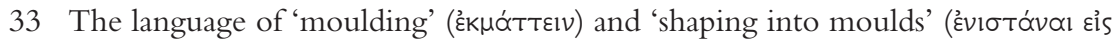
Toùs túrTous) at 396d-e picks up and extends Socrates' original concern with the 'soft', 'plastic' malleability of the young mind at $2.377 \mathrm{~b}$. Gorgias uses the lex-

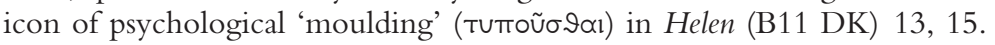


psychically fragmentative, multiplicatory tendency of mimesis suspect to Socrates in a more diffuse way. That is why, when he tries to get Adeimantus' agreement to a definition of two 'species' ( $\left.\varepsilon^{\prime} \delta \eta\right)$ or paradigms of narrative practice (396b ff., i. e. what I have called his second-order typology of lexis), the weight of his normative emphasis falls on selective use of mimesis, not its total elimination: he certainly deems it permissible, au fond, where 'good' characters are represented, but wants to limit its availability for impersonation of bad characters.

Before pressing a supplementary question about this position, we need to notice an element of complexity and even equivocation in Socrates' statement of his principles. At 396c-e he says:

(1) the decent or moderate person will be willing to recite/perform a mimetic presentation of a good character (taking on the persona

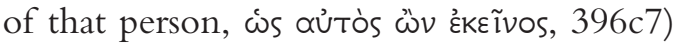

(1a) especially $\left(\mu \alpha \dot{\alpha} \lambda_{\imath} \sigma \tau \alpha\right)$ when such characters are depicted as acting well, but

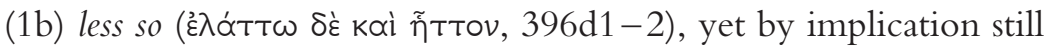
to some extent, when such characters are acting less well (under the influence of disease, sexual passion, drunkenness or 'some other mishap'); and

(2) the decent person will be unwilling to recite/perform seriously ( $\sigma \pi \circ \delta \delta \tilde{n}, 396 \mathrm{~d} 4$; cf. 397a3) the mimetic presentation of bad characters, except

(2a) 'briefly', when such characters do something good, or

(2b) the performance is undertaken 'for the sake of play' ( $\pi \propto \iota \delta i$ ãs xápıv, 396e2).

The qualifications in that statement - qualifications frequently omitted in scholarly references to the passage - are arresting but hard to elucidate or quantify. In particular, (1b) is of indeterminate scope, though it clearly blocks the inference that the only appropriate models of mimesis are ethically perfect characters and it seems to leave room for at least some kinds of tragic and comic scenarios. ${ }^{34}$ Equally, (2b) posits an exception

34 On this last point cf. Giuliano 2005, 52-4. That mimesis is restricted to ethically perfect characters is wrongly claimed by Gastaldi 1998, 368; Janaway

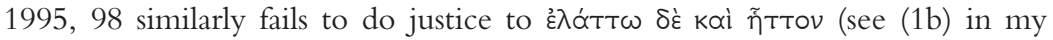
text) by saying that the good narrator will 'draw the line at enacting scenes in which a good man is less than perfect'. It is mistaken to suggest, as Morgan 2003, 106 does, that at 392c-8b 'direct discourse' or mimesis per se 'is morally 
whose implications are left wholly unelaborated but which could be farreaching. Would it be acceptable to participate in any mimesis provided one did so in a spirit of detached make-believe, holding back from or resisting emotional engagement? If so, what is the alternative or modified psychology that lies undeclared by this invocation of 'play', a term used deprecatingly by Socrates at Republic $10.602 \mathrm{~b}$ to characterise poetic mimesis in general? These are difficult questions to which no one has yet proposed fully cogent answers. ${ }^{35}$ What matters for my immediate purposes is that what is usually paraphrased by modern interpreters as an uncompromising set of restrictions on the permissibility of mimetic narrative is actually hedged around in a way which conveys something less than definitive prescriptiveness. This impression is underlined, I think, when the discussion enters its final phase. Here, having set up his two narrative species or paradigms ( $\left(\varepsilon^{\prime} \delta \eta\right)$, one predominantly using the single-voiced mode ("with a relatively small portion of mimesis in a long discourse', 396e7), the other predominantly or exclusively using the mimetic mode (397b1-2), Socrates proceeds, as with his original tripartite schema of narrative forms, to allow for 'mixture' or

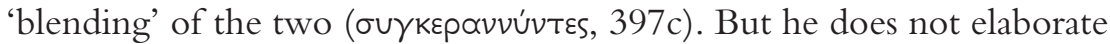
on what he understands by this last possibility, which is doubly perplexing: for one thing, the two species have just been defined as entailing a sharp ethical, not just a formal, contrast (396b-7b), so it is not easy to see what it could mean to blend the two without compromising (or refining) the definitions themselves; for another, Socrates calls both species 'unmixed' (o'kportos, 397d2), even though he has explained that each of the two will involve some degree of combination of plain with mimetic narrative (i.e., each will be precisely a compound or mixed form according to the original tripartition at $392 \mathrm{~d}) .{ }^{36}$ When, moreover, Adei-

reprehensible', or that 'imitation is dangerous and bad' tout court, Annas 1981, 95.

35 Ferrari 1989, 118-19 offers one interesting line of interpretation, though perhaps making too much of the idea of 'satirical' mimesis. It is pertinent that the phrase $\pi \propto ı \delta ı \tilde{s}$ Xápıv ('for the sake of play'), or something very like it, occurs in a number of other Platonic passages, including the famous critique of writing at Phdr. 276d (applicable, arguably, to Platonic dialogues themselves). See also esp. Plt. 288c (decorative and mimetic art in general), Criti. 116b (ornate architecture on Atlantis), Lg. 8.834d (equestrian and related contests).

36 Genette (1972) 1980, 162 n. 2 (where the reference should read '397d') erroneously conflates this later use of 'unmixed' with the terms of the earlier tripartition; Genette (1983) 1988, 18 correspondingly and misleadingly glosses mimetic narrative as 'impure - that is, mixed' (his italics). Among the more careful 
mantus declares his own preference for 'the unmixed mimetic imperso-

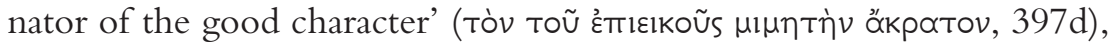
one could be forgiven for wondering whether he is referring exactly to the first of the species which Socrates had outlined: Adeimantus's wording hardly sounds as though it corresponds to 'a relatively small portion of mimesis in a long discourse' (396e7). The upshot of all this, I suggest, is that after the second-order typology at 396b-7d has been superimposed on the original formal typology of $392 \mathrm{c}-4 \mathrm{c}$, we are left not so much with a clear-cut taxonomy as with guidelines for a spectrum or sliding scale of narrative styles (each of them marked by an interplay between character, situation, tonal nuances, and diegetic form). And we are left to puzzle out for ourselves where particular genres, and, more importantly, individual works in those genres, are to be placed on that spectrum.

The gap between Socrates' impetus towards a decisive set of precepts for narrative form and the complex adjustments for which he makes provision at $396 \mathrm{c}-\mathrm{e}$ is only heightened by his curious hint at 397 c that selection of diegetic mode has to be made not only by

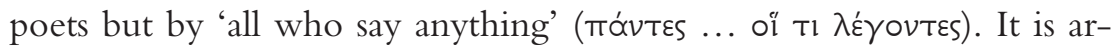
bitrary to restrict this phrase, which has attracted less comment than one might have expected, to public speakers, though it must include them. ${ }^{37}$ The phrase ostensibly embraces all discourse, at least all discourse with a narrative component - all diêgêsis of past, present or future (392d), which is, of course, a very large proportion of human discourse in general. If that is right, Socrates is asserting that all narrators, not just poets, face choices at every moment about how they present their accounts, and that they cannot avoid orientating themselves in relation not just to the formal alternatives of 'plain'/third-person and 'mimetic'/first-person narrative, but to all the consequences that these options bring with them for psychological perspective, emotional engagement or distance, and ethical evaluation. Yet Socrates neither develops his more general hint nor, so I have maintained, brings his critique of poetic narrative possibilities to an unequivocal conclusion. Another way of

treatments of the terminological/conceptual twists at $394 \mathrm{~d}-8 \mathrm{~b}$ are Blondell 2002, 236, Ferrari 1989, 118, Janaway 1995, 97-100.

37 Murray 1996, 181 takes the reference to be to public speakers. Vegetti 2007, 473 is one translator who favours the broader interpretation ("chiunque si esprima con discorsi'); cf. Giuliano 2005, 44-5. There is a connection with the similarly broad and vague clause at 396c1, 'whenever he [sc. the good man] has to

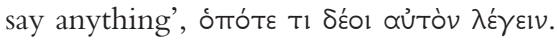


putting that point is to say that Plato does not, after all, give Socrates a fully fledged 'theory' of narrative. He gives him only a set of partial intuitions and incomplete arguments which converge on the legitimacy of probing at various levels (psychological, ethical, and ideological) the workings of voice, point of view, and other expressive aspects of form in any narrative discourse which has the power to shape and influence cultural patterns of experience.

This drives us back to a question which has often been posed but which eludes any easy answer. What is Plato's relationship as writer to the analysis of narrative which he places in Socrates' mouth? Two considerations which have figured in my reading of the passage matter greatly here: one, that Socrates' first formal typology (392c-4c) happens to omit or downplay possibilities (including the role of a primary narrator other than the author himself) which are important in Plato's own writing; the other, that the normative extrapolations which Socrates draws from that typology and which produce a further, second-order typology of diêgêsis (394d-8b) lay down some strong criteria but also introduce an element of flexibility into the perception of how narrative form can or should be employed for desirable ends. Between them, these considerations mean that Republic 392c-8b does not, as it stands, provide a ready-made yardstick by which to judge Plato's own writing. In particular, it is unjustifiably reductive to suppose, as is often done, that the passage articulates a generalised aversion to mimetic narrative per se and therefore stands in prima facie conflict with Plato's own general practice. The relationship between Socrates' arguments and the nature of the work in which they occur is a problem for any reflective reader of the Republic, especially since Socrates himself calls the thought-experiment of 'founding' the ideal city in words an exercise in muthos (376d) and thereby brings it within his own category of prose muthologia (392d). But it is not a problem that can be stated in terms of simple contradiction.

The problem becomes profound (in extent and difficulty), I suggest, when we take into account the less than consistent alignment between the presuppositions which appear to inform the two halves of the critique of poetry, i.e. the analysis of poetry as, in turn, logoi and lexis

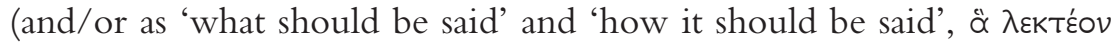

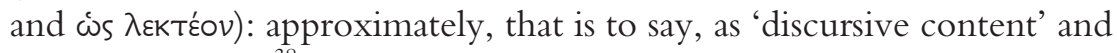
'discursive form' ${ }^{38}$ I shall have to limit myself here to a few compressed

38 Pace Laird 1999, 48-60 (but note his caution on 61-2), this distinction cannot 
claims about the earlier stages of the critique (376e-92c). In the first place, the discussion of poetic muthoi (a subset, remember, of logoi) seems scarcely to recognise the existence of diegetic form. Thus in Book 2 Socrates can use the formulation 'the poet says' (vel sim.) even when quoting from character speeches (though usually without mentioning that fact): cases in point are $379 \mathrm{~d}-\mathrm{e}$ (Iliad $24.527 \mathrm{ff}$., Achilles speaking; see below), 380a (Aeschylus fr. 154a.15-16 $\operatorname{Tr} G F$, Niobe speaking). In other words, in this phase of his analysis he largely ignores the presence or absence of mimesis as later defined at $392 \mathrm{~d}$ ff.: consider especially, in this connection, the string of seven Homeric quotations in quick succession at 386c-7b, three of them from character speeches, four in the narrator's voice, but without any markers of that difference. ${ }^{39}$ Even when Socrates does occasionally register the dramatic identity of a speaker, this does not always seem to impinge on his method of criticism: see for instance the citation at 383a-b of a speech by Thetis (Aeschylus fr. 305) whose attack on Apollo's truthfulness is held against the poet himself; and note Socrates' revealingly unqualified assertion that "when someone/anyone says such things about the gods, we shall be offended...'. One consequence of the factors just noted is a general impression that Socrates holds poets authorially responsible (i. e. ethically, not just causally) for what is 'said' in their work, regardless of the narrative form employed. When he adduces the special status of divine and heroic characters who, he assumes, possess an implicitly religio-ethical

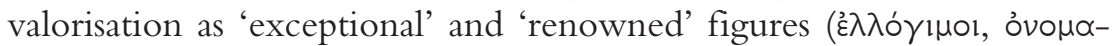
бтоi) within the culture's 'inherited conglomerate', Socrates refers equally to what such figures say or to what we are told about their behaviour. ${ }^{40}$ Diegetic form appears not, at this stage of the argument, to have any significance in its own right.

be equated with a narratological separation of 'story' (as raw or abstracted events) and 'narrative' (as their ordered disposition in a text), or 'histoire' and 'récit', 'fabula' and 'story' (or any other equivalent pair of terms). Although Socrates comes close to such a distinction in the lexis part of his analysis, especially when 'rewriting' the Chryses episode of Iliad 1 at 393d-4a, the larger logoi/lexis distinction is trickier: logoi, as indicated in my text, covers aspects of discourse which extend beyond narrativity.

39 I draw attention to some of the complex implications of these patterns of quotation in Halliwell 2000, 111-12.

40 For the relevance of heroic and semi-divine status, see esp. 387d-8a, 388e ( $\alpha$ \&́ous $\lambda$ óyou), 390d, with the application of the principle to the cases of Achilles and Priam at 388a-b. Cf. Socrates' use of the story of the Iliadic Achilles as a positive paradigm at $A p .28 \mathrm{~b}-\mathrm{d}$. 
But we can go further than this. In the first part of the critique Socrates seems not primarily to be concerned with 'narrative' as such, qua the plotting of particular events in time, but with general(isable) propositions (it is tempting to say 'messages') which he takes to be embodied in and expressed by narrative poetry - propositions, that is, such as 'gods are capable of evil, conflict and deceit' (cf. 377e-83c), 'death is the ultimate negation of everything' (cf. 386a-8b), 'good people are not always happy' (cf. 392a-c). It is such propositions (and elements of a potential 'worldview'), whether explicit or implicit, which he treats as the core of a work's communicative effect and to which his understanding of authorial responsibility chiefly applies. This notion of authorial responsibility is textually 'global', covering everything, it seems, in the composition and 'telling' of a muthos. It accordingly needs to be distinguished from the narrower notion of the voice of 'the poet himself' which in Book 3 Socrates identifies with plain or single-voiced diêgêsis, though that is not to deny that in reading the critique as a whole, in sequence, some of the force of the global paradigm of authoriality might be felt to carry over, a fortiori, into the detection of the poet's voice in the 'plain' narrative mode. What is most remarkable about the global premise of authorial responsibility in the first half of the critique of poetry is that in disregarding diegetic form it also appears to override dramatic psychology and in the process converts the viewpoints of characters into those of the poet himself. Perhaps the most striking instance of this is at $379 \mathrm{c}-\mathrm{d}$, where Socrates speaks scornfully

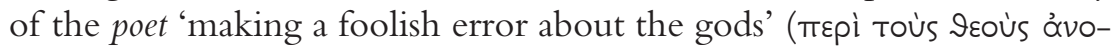

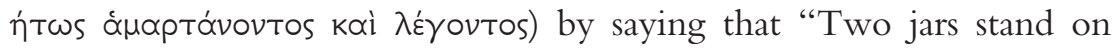
Zeus's floor...", as though Homer himself were necessarily endorsing the sentiments expressed by Achilles to Priam. Some readers of the Republic have been ready to jump to the conclusion that in passages such as this 'Plato' allows theological and moral concerns to erase any awareness of context or characterisation. But there is a double-sided problem with this inference. On the one hand, such a charge against Plato involves making the same hermeneutic mistake (by automatically equating the words of a character with the beliefs of the author) as Socrates seems to make in Plato's text. ${ }^{41}$ On the other hand, it is inconceivable that

41 Gould 2001, 315, in ascribing to Plato a failure to distinguish between author and narrator, unwittingly does the same thing himself. More generally, Gould resists what he sees as Plato's commitment to 'simple univocality of meaning' 
Plato himself, as the highly self-conscious writer of dialogues which contain many opposed and sometimes eristically antagonistic viewpoints, could have supposed that every author, whether in poetry or prose, necessarily subscribes to everything which he makes his characters say. Why then, we are left to wonder, does he show Socrates apparently resorting to such a supposition without any qualms?

It is hard to escape a sense of tension, or at the very least of incomplete harmonisation, between the models of 'poetics' (or meta-poetics) which Socrates adopts, and largely takes for granted, in the two blocks of argument at Republic 376e-92c and 392c-8b. In the first case, Socrates operates with an understanding of logoi as essentially the dominant or cumulative meanings (allegedly) conveyed by particular passages or entire works. He regards poets as globally responsible for these logoi and as lending them a kind of expressive endorsement even where they put them into the mouths of characters. To that extent, he analyses "what should be said' in poetry in a manner which not only is ostensibly independent of diegetic form but even appears to make consideration of such form redundant. The meanings Socrates finds communicated by the texts he cites can in that sense be described as 'supra-narrative' propositions, even though they are conceived of at the same time as 'schemata' or 'patterns' (тútrol, e.g. 379a) which inform whole classes of story, such as those of conflict between gods $(377 \mathrm{e}-8 \mathrm{~d})$. In the second half of the critique, by contrast, he develops a typology of diegetic form - an intricate two-stage typology, as I tried to show earlier which gives central prominence to the difference between first- and third-person narrative presentation, thereby distinguishing what is said by 'the poet himself' (now qua internal narrator, not as creator of the whole work) from what is said by characters or agents in the narrative and stressing the importance of how that distinction is handled by the choices of the writer. That is not to say that the two parts of the critique could not in principle be better harmonised than they are: even a passage such as 379c-d (cited above), which seems to erase the difference between plain narrative and mimesis, might be taken to depend on the silent assumption that the force of the 'two jars' passage is objectionable in part because of Homer's decision to attribute the thought it contains to the Iliad's chief hero, and at a juncture of supreme dramatic intensity in the structure of the poem. Here and elsewhere, Plato expects

(316, cf. 333-4), but he fails to bring to the Republic the open-minded hermeneutic which he thinks appropriate for Homer and drama. 
readers to have the knowledge to fill out for themselves the contexts from which Socrates often abruptly plucks his material (386c-7a is strongly suggestive in this respect).

But even if harmonisation of the two halves of the critique could be to some degree improved by spelling out tacit premises about speakers and circumstances, it would remain the case that Socrates evaluates poetic (and, more obliquely, prose) narrative from more than one perspective. It is part of the underlying momentum of the passage as a whole that we are shown how narrative (broadly construed) is open to questioning and interpretation on multiple levels. Although Socrates constructs a critical framework within which ethical (and 'theological') $)^{42}$ considerations trump all others, including those of factual 'truth' (see $378 \mathrm{a} 2$ ), this is not in itself sufficient to integrate all the strands of his argument, since we saw earlier that in his treatment of lexis Socrates acknowledges more than one way in which narrative form might be handled with a view to ethical ends, not least in the hints of variable permutations of character, situation, and tone at 396c-e. And here there is an important factor to be added from Plato's own writing. However uncertain we may feel about the applicability of Socrates' normative appraisal of diegetic form to the workings of Platonic dialogue itself, it is impossible to deny that Plato permits ethically discrepant, sometimes harshly discordant, voices to be sounded mimetically in parts of his work. A minimal inference from this is that either Platonic practice is less than seamlessly continuous with the position which Republic 3 ascribes to Socrates, or that Republic 3 itself cannot be taken to offer a comprehensive set of principles for the correlation of narrative form with ethical viewpoint.

But to that inference we can and must add a salient paradox. Principally because of its preoccupation with designing a system of education for the Guardian class of Callipolis, the discussion between Socrates and Adeimantus lays down principles for minds which, while capable of responding to, and being influenced by, poetic stories and characters, are assumed to be largely incapable of independent critical judgement. ${ }^{43}$ But Plato's own dialogue, by contrast, presupposes readers who are capable not only of following and engaging with dialectical argument, but

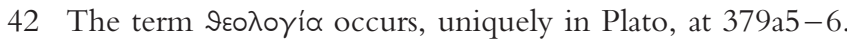

43 This is explicit in the well-known remark about allegorical interpretation at 2.378d: 'for the young person is not able to judge (kpívelv) where there is allegorical significance (úmóvola) or not'. 
also of tracking closely the narrative-cum-dramatic form in which the argument unfolds. Plato's own practice relies, therefore, on readers who have a more sophisticated sensitivity to the possibilities of narrative form than the audiences of poetry posited by Socrates' proposals. If, moreover, we recall once again that Plato's own practice is also in certain respects different from - and less straightforward than - the parameters which Socrates works with at 392c-4c, we have double grounds, I submit, for concluding that the typology of diegetic form and function in Republic Book 3 cannot be a complete 'Platonic' theory of narrative. Its interpretation paradoxically calls for a richer narrative (and conceptual) 'competence' than Socrates' prima facie thesis envisages.

I have been arguing in this paper that there is no fully integrated theory of narrative, let alone anything we can call 'Plato's theory' of narrative, to be found at Republic 3.392c-8b, and that the difficulties we encounter in pursuing the implications of this stretch of the text are deepened when taken in conjunction with the larger critique of poetic (and more than poetic) discourse at $2.376 \mathrm{e}-3.392 \mathrm{c}$. If I am right, the interest of Plato for narratology, as well as for the history of poetics in general, consequently lies not in the possibility of systematising certain views expressed in the dialogues into a putatively authorial theory. It lies, rather, in the challenge of coming to terms with the counterpoint between possibilities of 'theory' and 'practice' in the fabric of the works themselves and with the unresolved puzzles to which this counterpoint gives rise. Plato's own writing, which is the only place where we can hope to find 'Plato' at all, embodies a cumulative recognition that the scope and operations of narrative, whether in a wider or narrower sense of that category, will always exceed and outrun any attempt to theorise them. 